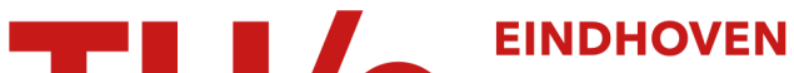 UNIVERSITY OF TECHNOLOGY
}

\section{RCS measurements, transformations and comparisons under cylindrical and plane wave illumination}

\section{Citation for published version (APA):}

Birchter, C. R., Balanis, C. A., \& Vokurka, V. J. (1994). RCS measurements, transformations and comparisons under cylindrical and plane wave illumination. IEEE Transactions on Antennas and Propagation, 42, 329-334. https://doi.org/10.1109/8.280718

DOI:

10.1109/8.280718

Document status and date:

Published: 01/01/1994

\section{Document Version:}

Publisher's PDF, also known as Version of Record (includes final page, issue and volume numbers)

\section{Please check the document version of this publication:}

- A submitted manuscript is the version of the article upon submission and before peer-review. There can be important differences between the submitted version and the official published version of record. People interested in the research are advised to contact the author for the final version of the publication, or visit the $\mathrm{DOI}$ to the publisher's website.

- The final author version and the galley proof are versions of the publication after peer review.

- The final published version features the final layout of the paper including the volume, issue and page numbers.

Link to publication

\section{General rights}

Copyright and moral rights for the publications made accessible in the public portal are retained by the authors and/or other copyright owners and it is a condition of accessing publications that users recognise and abide by the legal requirements associated with these rights.

- Users may download and print one copy of any publication from the public portal for the purpose of private study or research.

- You may not further distribute the material or use it for any profit-making activity or commercial gain

- You may freely distribute the URL identifying the publication in the public portal.

If the publication is distributed under the terms of Article 25fa of the Dutch Copyright Act, indicated by the "Taverne" license above, please follow below link for the End User Agreement:

www.tue.nl/taverne

Take down policy

If you believe that this document breaches copyright please contact us at:

openaccess@tue.nl

providing details and we will investigate your claim. 


\title{
RCS Measurements, Transformations, and Comparisons Under Cylindrical and Plane Wave Illumination
}

\author{
Craig R. Birtcher, Constantine A. Balanis, Fellow, IEEE, and V. J. Vokurka
}

\begin{abstract}
Monostatic RCS measurements of a long bar (at $X$-band) and of a scale model aircraft (at $C$-band) were performed under the quasi-plane wave illumination produced by a dual parabolic-cylinder CATR. At Arizona State University's ElectroMagnetic Anechoic Chamber (EMAC) facility, these measurements were repeated under the cylindrical wave illumination produced by a March Microwave Single-Plane Collimating Range (SPCR). The SPCR measurements were corrected using the "reference target method." The corrected SPCR measurements are in good agreement with the CATR measurements.
\end{abstract}

\section{INTRODUCTION}

$\mathbf{T}$ THE TECHNIQUES for determining far-field antenna and RCS patterns at short distances are numerous and well known. One class of techniques involves reflecting the spherical phasefront of a source antenna from one or two curved metal reflectors. These systems, referred to as Compact Antenna Test Ranges (CATRs), are used to synthesize planar phasefronts [1], [2]. Using a CATR, far-field patterns can be measured at short distances directly. Another class uses Near-Field to Far-Field (NF/FF) transformations to analytically predict far-field radiation patterns from measurements performed over a surface that is near the test antenna [3], [4], [5].

At Arizona State University's ElectroMagnetic Anechoic Chamber (EMAC) facility, a hybrid approach is used to determine far-field radiation and scattering patterns. A March Microwave Single-Plane Collimating Range (SPCR) semicompact antenna test range generates a quiet zone comprised of cylindrical wavefronts [6]. The SPCR reflector has a parabolic curvature in the vertical plane and is flat in the horizontal plane. Fig. 1 shows the spherical phasefronts from the feed antenna collimated by the SPCR in the vertical plane while they continue to spread horizontally. Thus the virtual image of the SPCR feed is a vertical line source, as illustrated schematically in Fig. 2. For targets that are large relative to the curvature of the cylindrical wavefront, a one-dimensional analytical algorithm transforms the cylindrical wave (nearfield) measurements into the desired plane wave (far-field) results.

Manuscript received August 12, 1992; revised August 27, 1993.

C. R. Birtcher and C. A. Balanis are with the Department of Electrical Engineering, Telecommunications Research Center, Arizona State University, Tempe, Arizona 85287-7206.

V. J. Vokurka is with the Department of Electrical Engineering, Eindhoven University of Technology, Eindhoven, The Netherlands.

IEEE Log Number 9215686.
The impetus for utilizing this hybrid approach is threefold: quiet zone size, NF/FF transformation efficiency, and cost. Due to the cylindrical spreading of the wavefronts, the horizontal-plane quiet zone is much larger (relative to the dimensions of the reflector) than that produced by conventional CATRs. Because the fields are collimated in the vertical plane, the NF/FF transformation is a simple and efficient one-dimensional algorithm. Additionally, a single pattern cut measured in the near-field of a cylindrical wave can be transformed to the far-field. Using other NF/FF transformations, comparatively prodigious amounts of near-field data must be measured, and a more computationally intensive algorithm is needed, to predict the far-field patterns. Because this semicompact range has a single reflector that is curved in only one dimension, it can be manufactured to a given surface accuracy more economically than one doubly-curved reflector, or a dual-reflector, CATR.

Comparisons of measurements performed under cylindrical and plane wave illumination demonstrate the efficacy of the SPCR and the RCS correction algorithm. Two targets and their monostatic RCS measured with a dual parabolic-cylinder CATR were available. The targets, a $2.0 \mathrm{~m}$ long precision bar and a scale model aircraft, were measured at EMAC for the frequencies, orientations, and angular positions which correspond to the CATR measurements. The corrected cylindrical wave measurements are in very good agreement with the CATR plane wave measurements.

\section{RCS TRANSFORMATION}

The "reference target method" correction algorithm was originally proposed as a technique to extend the quiet zone of CATR's for antenna pattern measurements [7]. The context of the algorithm has been extended to include RCS pattern measurements in computer software developed by March Microwave [8], [9].

At the EMAC facility, the algorithm is used to 'transform' RCS patterns measured in the near-field of the cylindrical wavefront into far-field patterns; however, the algorithm is not a NF/FF transformation in the conventional sense. The algorithm corrects for all deviations of the illuminating field from that of an ideal plane wave. Correction coefficients that are related to the inverse of these deviations, in both amplitude and phase, are calculated for a region of space equal to or greater than the dimensions of the test target. Convolving the correction coefficients with the RCS pattern of the target 


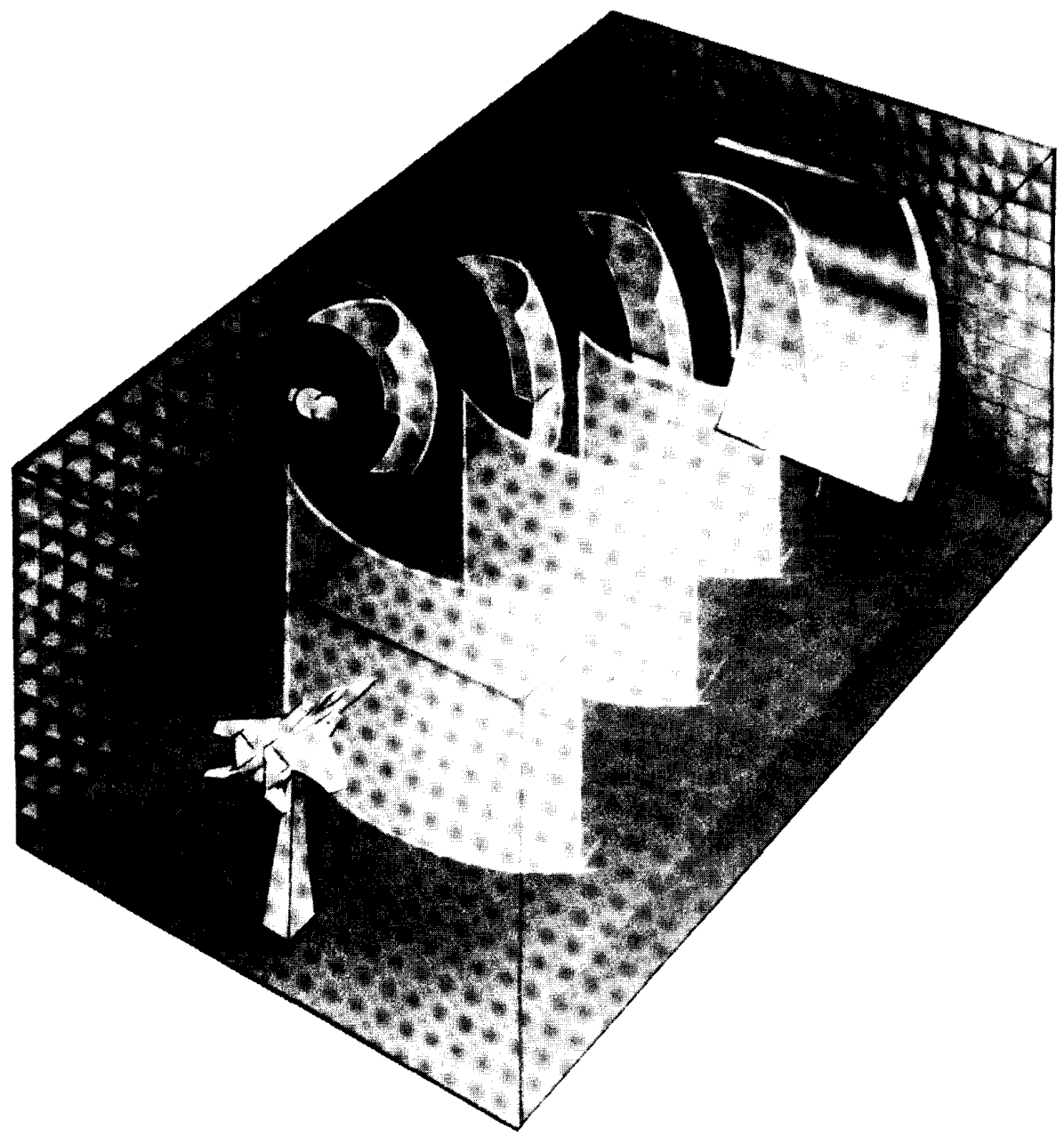

Fig. 1. Artist's rendering of the production of a cylindrical-wave quiet zone by the Single-Plane Collimating Range (SPCR).

removes from the measurements errors due to the non-plane wave illumination.

To determine the field distribution in the quiet zone, the RCS of a reference target is measured as a function of aspect angle. The reference target can be any long straight metal bar or cylinder. The distribution of the illuminating field along the surface of this reference target is essentially related to its RCS by a Fourier transform. The transverse field distribution could also be obtained by probing the quiet zone directly, but the assembly and allignment of a scanner would be time consuming.

To derive the correction algorithm, consider the twodimensional case of a bar of length $L$ rotated about its center as shown in Fig. 3. The Physical Optics (PO) current $\vec{J}_{p}\left(x^{\prime}\right)$ along the length of the bar under some arbitrary illumination is given by

$$
\vec{J}_{p}\left(x^{\prime}\right)=2 \hat{n} \times \vec{H}_{i}\left(x^{\prime}\right)
$$

where $\hat{n}=$ a unit vector normal to the surface of the bar

$\vec{H}_{i}=$ the incident magnetic field along the surface of the bar. Assume that the electric and magnetic fields are related by

$$
\vec{H}_{i}\left(x^{\prime}\right)=\frac{\hat{k} \times \vec{E}_{i}\left(x^{\prime}\right)}{\eta_{\mathrm{o}}}
$$

where $\hat{k}$ is the propagation vector and $\eta_{\mathrm{o}}$ is the free space wave impedance. Let the incident electric field along the surface of the bar be in the form of two complex parts:

$$
\vec{E}_{i}\left(x^{\prime}\right)=\hat{e}_{i}\left[E_{p}\left(x^{\prime}\right) e^{j k x^{\prime} \sin (\alpha)}\right]\left[g\left(x^{\prime}\right)\right]
$$

where

$E_{p}\left(x^{\prime}\right) e^{j k x^{\prime} \sin (\alpha)}=$ the electric field along the surface of the bar under ideal plane wave illumination

$g\left(x^{\prime}\right) \quad=$ the complex distribution function which describes the deviation of the actual illumination from that of an ideal planar wavefront

$\hat{e}_{i} \quad=$ the polarization vector of $\vec{E}_{i}$ 
To determine the fields scattered by the bar, the vector potential $\vec{A}$ must be found. The vector potential is related to the PO current by

$$
\vec{A}=\frac{\mu}{4 \pi} \int_{-\frac{L^{\prime}}{2}}^{\frac{L^{\prime}}{2}} \vec{J}_{p}\left(x^{\prime}\right) \frac{e^{-j k R^{\prime}}}{R^{\prime}} d x^{\prime}
$$

Using the far-field approximation, (4) reduces to

$$
\vec{A} \approx \frac{\mu}{4 \pi R} e^{-j k R} \int_{-\frac{L^{\prime}}{2}}^{\frac{L^{\prime}}{2}} \vec{J}_{p}\left(x^{\prime}\right) e^{j k x^{\prime} \sin (\alpha)} d x^{\prime}
$$

The far-field scattered electric field $\vec{E}_{s}$ is related to the vector potential by

$$
\vec{E}_{s}=j \omega[\hat{k} \times(\hat{k} \times \vec{A})]
$$

Replacing $\vec{A}$ in (6) with (5) leads to

$$
\vec{E}_{s}(\alpha) \approx \frac{j \omega \mu}{4 \pi R} e^{-j k R}\left[\hat{k} \times\left(\hat{k} \times \int_{-\frac{L^{\prime}}{2}}^{\frac{L^{\prime}}{2}} \vec{J}_{p}\left(x^{\prime}\right) e^{j k x^{\prime} \sin (\alpha)} d x^{\prime}\right)\right]
$$

Substituting from (1) and (2) into (7) yields

$$
\begin{aligned}
\vec{E}_{s}(\alpha) \approx & \frac{j \omega \mu}{4 \pi R} e^{-j k R} \int_{-\frac{L^{\prime}}{2}}^{\frac{L^{\prime}}{2}} \hat{k} \\
& \times\left(\hat{k} \times\left(2 \hat{n} \times \frac{1}{\eta_{\circ}}\left(\hat{k} \times \vec{E}_{i}\left(x^{\prime}\right)\right)\right) e^{j k x^{\prime} \sin (\alpha)} d x^{\prime}(8)\right.
\end{aligned}
$$

Performing the indicated vector operations assuming a linearly polarized TEM incident field and substituting from (3) reduces (8) to

$$
\vec{E}_{s}(\alpha) \approx \frac{j 2 \omega \mu}{4 \pi R \eta_{\circ}} e^{-j k R} \int_{-\frac{L^{\prime}}{2}}^{\frac{L^{\prime}}{2}} \hat{e}_{2} E_{p}\left(x^{\prime}\right) e^{j 2 k x^{\prime} \sin (\alpha)} g\left(x^{\prime}\right) \cos (\alpha) d x^{\prime}
$$

Translating the coordinates from along the bar to along the $x$-axis in (9), so that

$$
\begin{aligned}
x & =x^{\prime} \cos (\alpha) \\
d x & =\cos (\alpha) d x^{\prime}
\end{aligned}
$$

and letting $E_{p}(x)$ include the constant term $C$, where

$$
C=\frac{j 2 \omega \mu}{4 \pi R \eta_{\circ}} e^{-j k R}
$$

yields

$$
\vec{E}_{s}(\alpha) \approx \int_{-\frac{L}{2}}^{\frac{L}{2}} \hat{e}_{i} E_{p}(x) e^{j 2 k x \tan (\alpha)} g(x) d x
$$

Substituting $u=2 k \tan (\alpha)$ into (10) and dropping the vector notation yields the complex amplitude of the electric field scattered from the bar, which can be expressed as

$$
E_{s}(u) \approx \int_{-\frac{L}{2}}^{\frac{L}{2}} E_{p}(x) e^{j u x} g(x) d x
$$

When the incident illumination of the bar is an ideal plane wave,

$$
g(x)=1, \quad-\frac{L}{2} \leq x \leq \frac{L}{2}
$$

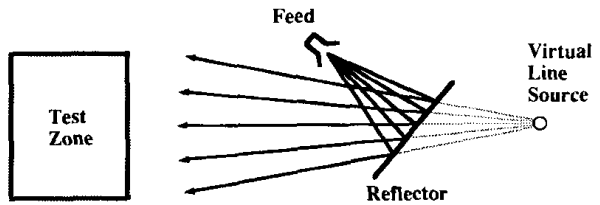

(a)

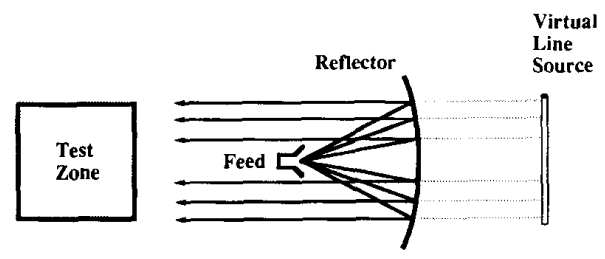

(b)

Fig. 2. Schematic representation of the Single-Plane Collimating Range. (a) Top view: horizontal spreading. (b) Side view: vertical collimation.

\section{Source}
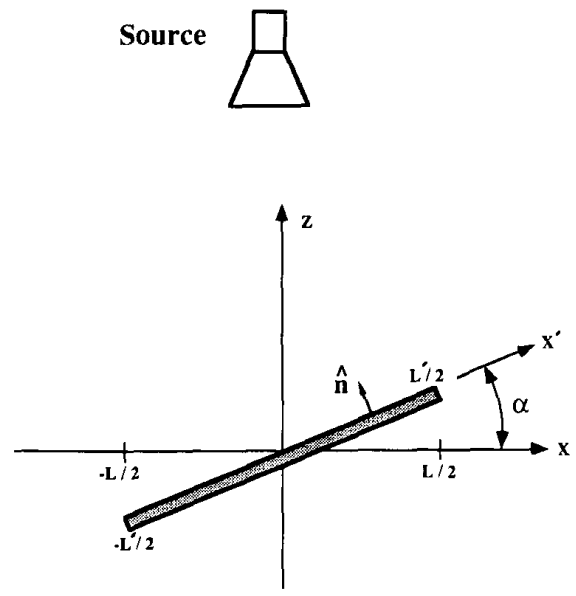

Fig. 3. Geometry of two-dimensional scattering.

Then $E_{s}$ reduces to $E_{s i}$, the electric field scattered from the bar under plane wave illumination

$$
E_{s i}(u) \approx \int_{-\frac{L}{2}}^{\frac{L}{2}} E_{p}(x) e^{j u x} d x
$$

Because there are no contributions to the scattered fields outside the region $-\frac{L}{2} \leq x \leq \frac{L}{2}$, the limits of integration can be extended to infinity. Thus (11) and (13) can be expressed in the form of Fourier Transforms as

$$
E_{s}(u) \approx \int_{-\infty}^{\infty} E_{p}(x) e^{j u x} g(x) d x
$$

and

$$
E_{s i}(u) \approx \int_{-\infty}^{\infty} E_{p}(x) e^{j u x} d x
$$


The electric fields scattered by the bar under nonplanar illumination $E_{s}$ can be measured as the monostatic RCS of the bar. The deviations of the illumination from an ideal plane wave $g(x)$ can be deduced from the measured RCS versus angle of a long straight reference bar. By deriving a relationship between (14) and (15), the errors due to the non-ideal illumination can be removed from the measured scattering pattern of the target bar to yield $E_{s i}$. Let a function called the "correction spectrum" be defined as

$$
Q(u)=\int_{-\infty}^{\infty} \frac{1}{g(x)} e^{j u x} d x
$$

Then

$$
E_{s i}(u)=E_{s}(u) * Q(u)=\int_{-\infty}^{\infty} E_{s}(v) Q(u-v) d v
$$

Rewriting $Q(u)$ as an infinite sum of delta functions, we have

$$
Q(u)=\sum_{n=-\infty}^{\infty} q_{n} \delta\left(u-\frac{2 \pi n}{L}\right)
$$

and

$$
q_{n}=\int_{-\frac{L}{2}}^{\frac{L}{2}} \frac{1}{g(x)} e^{\frac{j 2 \pi n x}{L}} d x
$$

where $q_{n}$ are termed the correction coefficients. Substituting $Q(u)$ from (18) into (17) yields

$$
E_{s i}(u) \approx \sum_{n=-\infty}^{\infty} q_{n} E_{s}\left(u-\frac{2 \pi n}{L}\right)
$$

Thus, errors in the RCS pattern of a test target, due to deviations of the illumination in the plane of rotation of the reference target, can be removed by summing the products of the response measured under the arbitrary illumination $E_{s}$ and the correction coefficients $q_{n}$ 's to obtain the corrected response $E_{s i}$ as indicated in (20).

\section{MEASUREMENTS AND COMPARISONS}

For accurate correction, the length of the reference target and the angular span of the reference target measurement should exceed that of the test target. This accounts for the diminishing of the synthesized plane wave zone caused by the effects of the ends of the reference target. The reference target utilized to correct the SPCR measurements presented here is a $5 \mathrm{~cm} \times 5 \mathrm{~cm} \times 2.44 \mathrm{~m}$ aluminum bar with all four surfaces milled flat. The RCS of this reference bar was measured for each of the test target measurement configurations (frequency, polarization, etc.) for angles of $-40^{\circ}$ to $+40^{\circ}$.

The precision metal bar test target has a $5.0 \mathrm{~cm}$ square cross section and one highly polished broadside surface. The bar measurements were made in the frequency band $7.5-12.0 \mathrm{GHz}$ for both $\mathrm{VV}$ and $\mathrm{HH}$ polarizations. The target was measured at azimuthal angles from $-30^{\circ}$ to $+30^{\circ}$ in steps of $0.1^{\circ}$, where zero degrees corresponds to broadside.

Fig. 4 is an example of the uncorrected RCS of the 2.0 $\mathrm{m}$ bar measured under the SPCR cylindrical wave illumination compared to the CATR measurement. The RCS pattern

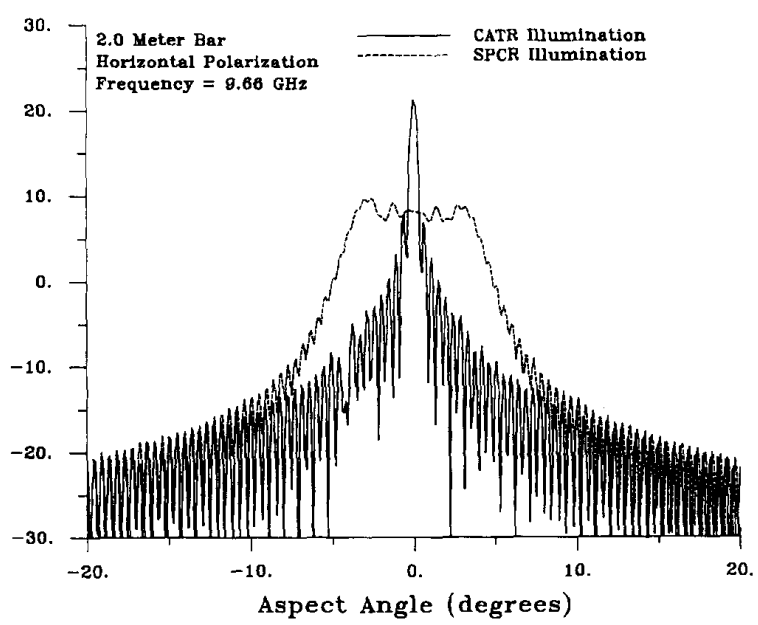

Fig. 4. RCS of a $2.0 \mathrm{~m}$ long precision bar at $9.66 \mathrm{GHz}$ and horizontal polarization (measured with the SPCR (uncorrected) and with a dual-parabolic CATR).

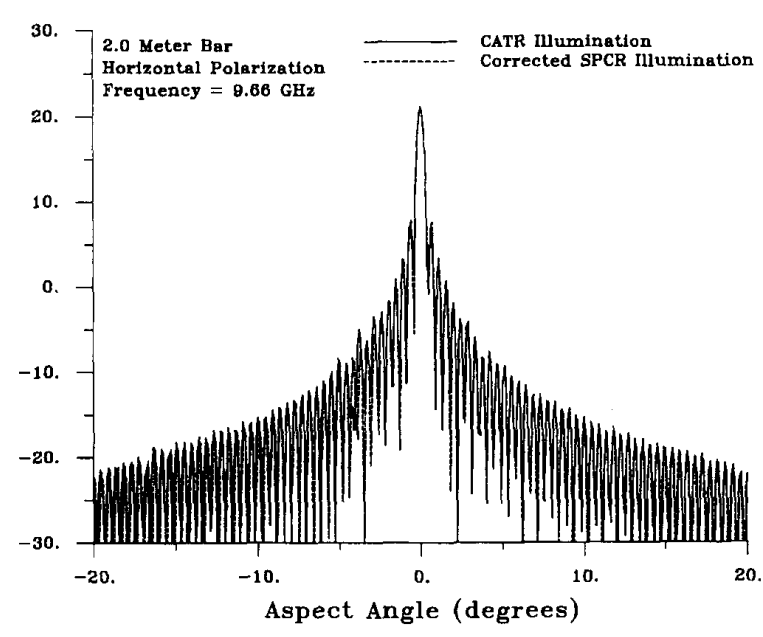

Fig. 5. RCS of a $2.0 \mathrm{~m}$ long precision bar at $9.66 \mathrm{GHz}$ and horizontal polarization (measured with the SPCR (corrected) and with a dual-parabolic CATR).

measured under cylindrical illumination deviates considerably from that measured under essentially plane wave illumination. Applying the reference target method correction algorithm to this measurement results in the pattern shown in Fig. 5, again compared to the CATR measurement. The CATR and corrected SPCR measurements are in excellent agreement.

Measurements of a scale model aircraft demonstrate the application of the reference target method to a topologically complex target. The scale model is a $52^{\prime \prime}(132 \mathrm{~cm})$ long, $36^{\prime \prime}(91 \mathrm{~cm})$ wingspan silver painted fiberglass drone. Because optimum correction occurs in a small angular region centered about zero degrees azimuth, the SPCR measurements of the drone were separated into $30^{\circ}$ segments. After correction the segments were re-assembled into the $360^{\circ}$ pattern. 


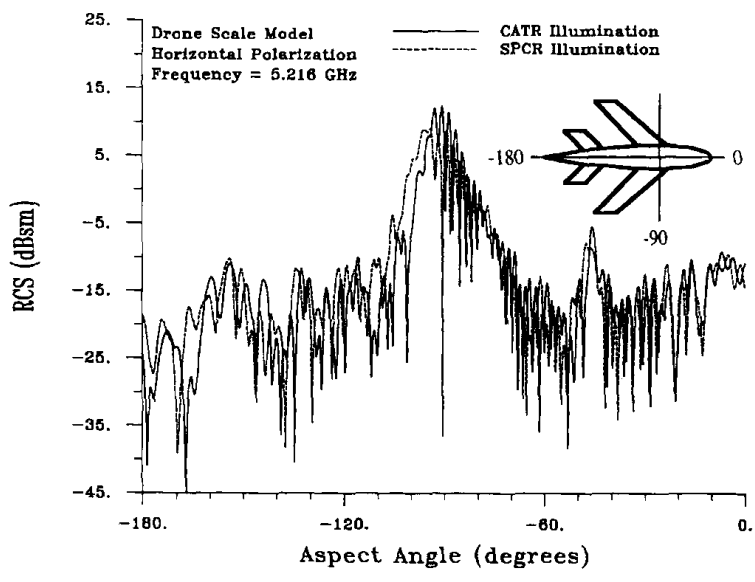

Fig. 6. RCS of a scale model drone aircraft at $5.216 \mathrm{GHz}$ and horizontal polarization (measured with the SPCR (uncorrected) and with a dual-parabolic CATR).

The measured patterns are of the yaw plane with zero degrees pitch and roll. The separation between the rotation center of the model and the virtual line source of the SPCR was $12.91 \mathrm{~m}$ : approximately $21 \%$ of the $2 D^{2} / \lambda$ distance. The horizontal polarization case at $5.216 \mathrm{GHz}$ is presented here. The CATR measurement and uncorrected SPCR measurement are compared in Fig. 6. Fig. 7 shows the CATR and corrected SPCR measurement. It is interesting to observe that, although the reference target method applies rigorously only along a line in cross-range, corrections occur for targets with significant down-range dimensions. Note particularly the $-20^{\circ}$ to $0^{\circ}$ region of Figs. 6 and 7. This orientation corresponds to maximum down-range/minimum cross-range dimensions of the target, yet the correction is very apparent. This example corroborates other measurements and simulations which suggest that targets within the cylindrical volume of space swept out by the reference bar are corrected. The most obvious discrepancies between the CATR and corrected SPCR measurements occur near tail-on incidence $\left(-180^{\circ}\right.$ to $\left.-135^{\circ}\right)$. Significant effort was made prior to the SPCR measurements to ensure that the target support was true as a function of aspect angle. Additional measurements were performed with small changes in the pitch orientation of the model. After correction, we found that the comparison near $-180^{\circ}$ was improved over that of Fig. 7, but that the comparison near nose-on incidence $\left(\right.$ zero $\left.^{\circ}\right)$ was worse. We conclude from this that there was a significant wobble in the dielectric foam target support at the CATR facility. Shadowing may be another factor contributing to this discrepancy. At angles near $-180^{\circ}$, the tail of the model aircraft shadows the wings and fuselage considerably. Shadowing represents an inherent error in NF/FF techniques, as no generalized correction or transformation exists that will account for the differences between near-field and far-field shadowing of one part of a target by another part.

\section{CONCLUSION}

The Single-Plane Collimating Range has been implemented at ASU's ElectroMagnetic Anechoic Chamber facility to pro-

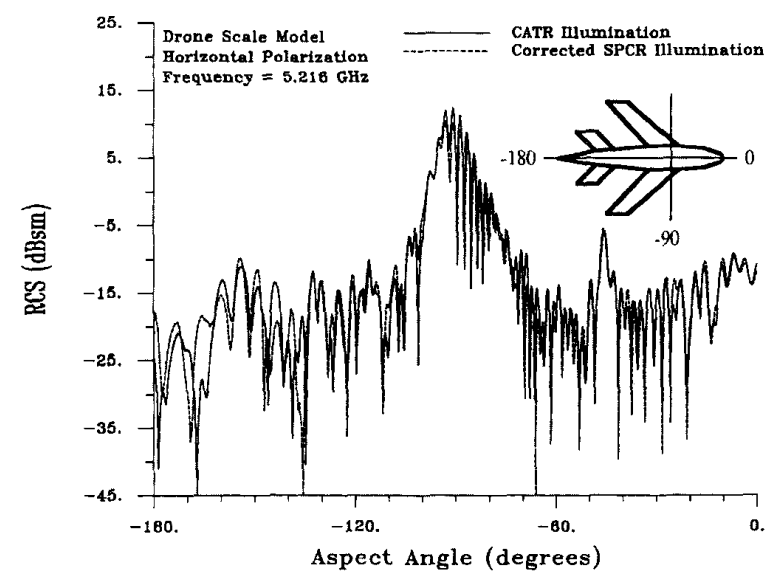

Fig. 7. RCS of a scale model drone aircraft at $5.216 \mathrm{GHz}$ and horizontal polarization (measured with the SPCR (corrected) and with a dual-parabolic CATR).

duce precision cylindrical wavefronts for antenna and RCS measurements. RCS measurements performed under cylindrical wave illumination exhibit considerable discrepancies from those performed under plane wave illumination; however, applying the "reference bar method" to the bar and drone SPCR measurements results in very good agreement with CATR measurements.

\section{REFERENCES}

[1] R. C. Johnson and C. E. Ryan, "Compact range technology and the marketplace," Microwaves \& RF, pp. 135-138, May 1987.

[2] R. C. Johnson, "Introduction to compact ranges," Proceedings of the Compact Range Workshop, Philadelphia, PA, June 13, 1986.

[3] A. D. Yaghjian, "An overview of near-field antenna measurements," IEEE Trans. Antennas Propagat., vol. AP-34, pp. 30-45, Jan. 1986.

[4] D. T. Paris, W. M. Leach, Jr. and E. B. Joy, "Basic theory of probe-compensated near-field measurements," IEEE Trans. Antennas Propagat., vol. AP-26, pp. 373-389, May 1978.

[5] J. Brown and E. V. Jull, "The prediction of aerial radiation patterns from near-field measurements," Proc. IEEE, vol. 108B, pp. 635-644, Nov. 1961.

[6] C. R. Birtcher, C. A. Balanis and V. J. Vokurka, "Quiet Zone Scan of the Single-Plane Collimating Range," AMTA Proceedings, Boulder, CO, Antenna Measurement Techniques Association, pp. 4.37-4.42, Oct. 1991.

[7] L. D. Bakhrakh, I. V. Kaplun and A. P. Kurochkin, "Determination of Parameters of Antennas Illuminated by a Nonplanar Wave," Radio Eng. Elect. Physics, vol. 20, no. 12, pp. 1-8, Dec. 1975.

[8] J. van Damme, "Correction Technique on Indoor RCS Measurements," Technical University of Eindhoven Report ET-16-86, Eindhoven, The Netherlands, Feb. 1987.

[9] C. R. Birtcher, "The Electromagnetic Anechoic Chamber at Arizona State University: Characterization and Measurements," M.S. Thesis, Arizona State University, Tempe, AZ, May 1992.

Craig R. Birtcher, for a photograph and biography, see p. 1389 of the October 1993 issue of this TRANSACTIONS.

Constantine A. Balanis, (S'62-M'68-SM'74-F'86), for a photograph and biography, see p. 1389 of the October 1993 issue of this TRANSACTIONS. 


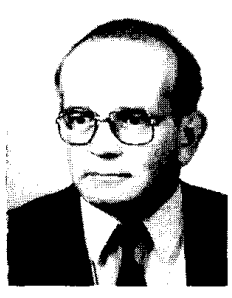

Vaclav J. Vokurka received the M.S. and Ph.D.

degrees in electrical engineering from Eindhoven

University of Technology, Eindhoven, The Nether-

lands, in 1973 and 1977, respectively.

From 1973 to 1977 , he was a research scientist at

the Netherlands Foundation for Scientific Research

(Z.W.O.). In 1978, he joined the Electromagnetics

Group at Eindhoven University, where he is currently an Associate Professor.

His research interests include antenna and feed design, computational electromagnetics, SAR and ISAR processing techniques, target identification and detection, and new methods for scattering and pattern determination. 